\title{
MBE for Barbara Chadwick
}

Professor Barbara Chadwick has been made an MBE in the Queen's New Year's Honours, for services to paediatric dental health. For most of her 35-year career, she has been based at Cardiff University School of Dentistry, most recently as Director of Education and Students. Professor Chadwick has worked as a researcher, clinician and teacher in paediatric dentistry, and has just retired. Commenting on her award, she said: 'As a children's dentist, you practise all aspects of dentistry, oral surgery, restorative and periodontics. You do a little bit of everything, constrained only by the age of the patients who need you as their advocate'.

Among her achievements, Professor Chadwick is particularly proud of the number of her dental students who have chosen paediatric dentistry as a career, some now working as specialists and consultants in paediatric dentistry. Professor Chadwick said: 'I have only succeeded because I have been lucky to work with insightful and thoughtful people. They nurtured me and in turn I hope I have been able to nurture the next generation of dentists. I have been one small cog in many enterprises'.

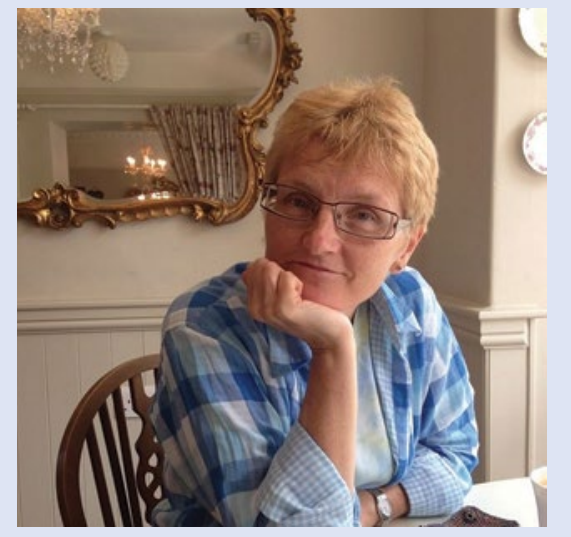

\section{BDA AGMs}

The East Midland

Branch AGM will be held online on

Wednesday 3 February

2021 at 18.30 .

Please ensure

you register your

interest in attending

at www.bda.org/bse in order to receive

the link to access the AGM or email

branchsectionevents@bda.org.

\section{Notice of death}

We are sad to announce the recent death of Edward James of Llanelli, former President of Llanelli RFC and the tennis umpire when John McEnroe bawled 'You cannot be serious' at Wimbledon in 1981. 